\title{
ARE WE HUMAN, OR ARE WE DENTISTS?
}

There are often moments in life when you can pinpoint exactly where you were, what you were doing and how you felt. From the ecstasy of your wedding to the moment you found out about a family bereavement, those feelings stay with you for the rest of your life. As dental professionals, it is understandable that, given the pressures exerted by UDAs and the way the contracts are, many patients will be treated and forgotten about by the time the next person is in the chair.

But what if that next person is a twoyear-old child? What if their decay is rampant? What if you know the only option you have is to send them to hospital for a full clearance? Bearing in mind more than 26,000 five to nine-year-olds find themselves in this exact position, that's a lot of small children you are sending to a world of pain. So how do you sleep at night? Do you seek solace in a wellknown malt drink to send you to sleep, or is it more complicated than that? News editor David Westgarth went to St George's University Hospital in London to meet Richard Porter (RP), Lexy Lyne (LL), Pratima Dahal (PD), Richard Johnson (RJ) and Lee Foo (LF), who find themselves in this position every day.

\section{I guess the first question is how do you get out of bed every morning knowing you're coming into work to remove body parts from children?}

RJ I have been doing the GA list for around three years now. In that time I have seen a tremendous amount of children. I can't begin to tell you what impact treating distressed children has on the entire team caring for them. You just can't quantify it. Speaking as a healthcare professional you have to try and filter out the emotion to ensure you're focused on the job at hand, but that doesn't always work. Some patients get to you more than others, and in my case it's the children with significant anxiety that are the hardest to cope with.

\section{Is there one specific incident that sticks in your head?}

RJ It's always the children who have severe anxiety issues. I have

\section{'I still found it emotionally distressing and quite shocking to see a child rendered unconscious because of something totally preventable'}

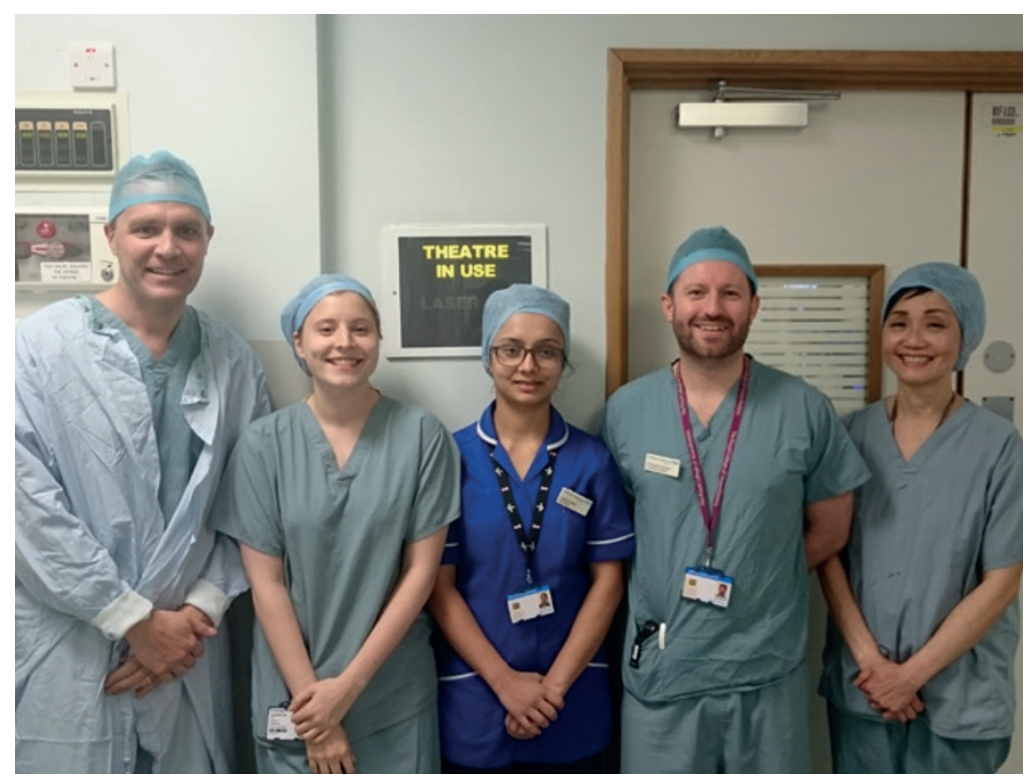

(L-R) Richard Porter, Consultant in Restorative Dentistry; Lexy Lyne, Dental core trainee; Pratima Dahal, Dental nurse; Richard Johnson, Consultant in Paediatric Anaesthesia; Lee Foo, Associate Specialist in Paediatric Dentistry

seen children so beside themselves with anxiety they are virtually impossible to treat. We get children in here as young as two years of age. It takes a strong cup of coffee to get in the right frame of mind for those.

\section{What sort of coping mechanisms do you have to get you through the day?}

LL You compartmentalise things. When children are referred here and they come for a new patient assessment and the treatment plan is formed, I guess that's when it starts to hit home that we're treating a small child. As our care pathway is so smooth and efficient - and it has to be given the stress we're under you end up dealing with a little bit at a time, which does make it more manageable.
RP Because I treat children on a less frequent basis than Richard and Lexy it always seems new to me. I have talked about this with colleagues before who have all said - like Lexy has just commented - that you become a bit more methodical and professional because they are your patient and you have to treat them. You have to harden up for the child's benefit to relieve them of the pain. You get emotionally geared up to deal with it, but I don't have that. Recently in theatre we treated one boy and although the process went incredibly well, as a parent and someone who doesn't treat children often it was incredibly hard for me.

I still found it emotionally distressing and quite shocking to see a child rendered unconscious because of something totally preventable. I thought this person has done 
nothing wrong and yet they find themselves here, lying unconscious on a table, ready to undergo a painful and stressful procedure. I didn't like it and I don't think I ever will. If I'm being honest with myself it's probably why I didn't look at paediatric dentistry in more detail as a career path, as I definitely knew I wouldn't be emotionally capable of treating child after child.

PD When I arrived here and attended surgery I was shocked. I remember having to leave the room. I felt totally helpless and had a funny feeling in my stomach. You can't ever be prepared for seeing that for the first time.

LL It's a sad thing to admit, but by the time I arrived here at St George's I was used to it. You have to view it as what's best for the child. You're in a care-giving environment, and if hurting them is how to do that in the long-term, so be it. I was saying to Dr Porter this week that at the time, if the child is crying and upset in pain, you just have to remain as cool and calm as possible, but when they're gone I can often feel myself shaking.

\section{So how do you retain your focus?}

LL You almost become a mechanic when you are actually doing the surgery, as you are focused on fixing the problem. You focus on understanding the problem - that this is a small child with multiple infected or painful teeth because of the sugar in their diet - at a different time to the surgery. So that would be, for example, at the initial visit in the dental department.

This means on the day when it comes to removing all these teeth, you leave behind the emotional stuff and just fix the problem, because that is the job at hand for the day.

\section{Do you find the parents lack the knowledge to give their child a good start in life, or do the parents know what sugar does but they overlook it, perhaps because it's easier and cheaper?}

LL I have found that in the majority of cases parents know what harm sugar can cause, but they think it's normal for their child to have large amounts of sugar. When we're in the process of completing a dietary investigation parents often tell us 'they don't have that much sugar', but digging deeper we find the child is having a sugary drink and snack every day when they come home from school. Because that's how it has always been they see it as the norm.

Richard, you see adults all the time, many of whom are parents. What do you think? Do you think as a parent you look at things differently? Do they treat their own oral health differently to that of their child?

RP I have a very strong opinion on this and have been outspoken on many occasions. Virtually everyone knows sugar causes decay. People think that if they brush their teeth twice a day they're doing a good job and can eat what they want. The problem is sugar is everywhere in abundance. It is in food and drinks we are lead to believe are healthy. People say to me they have had a glass of orange juice with a meal because it's the healthy alternative, when the reality is very different.

Drinks companies and food manufacturers use sugar to sell their products. We all make our own choices, except for one group; children. Children rely on their parents to make decisions for them. Every single parent will love their child more than anything in the world, but they are making some ill-informed choices that have disastrous consequences for their child, for the NHS and for people waiting for urgent care.

\section{Does the fact you're whipping out teeth from children become even harder to comprehend when you realise it's totally preventable?}

RP Absolutely 100\%. Because I don't treat children regularly I often look at the situation from a financial viewpoint. The burden on the wider NHS is enormous. If us six were to sit in a smoke-filled room, because we're an evil, sinister bunch, and thought 'right, how can we cause children to be hospitalised '...when it comes to removing all these teeth, you leave behind the emotional stuff and just fix the problem' and what's the most efficient way of doing it', hiding sugar in food stuffs would be our answer and we'd be very proud of ourselves. The reason? We hospitalise more children due to tooth decay than we do for any other reason. It's completely preventable and downright appalling. It wastes millions of pounds and causes stress to tens of thousands of children.

RJ I agree. I see things in a wider context. I anaesthetise children for a tremendous amount of procedures and I see a massive amount of childhood obesity, which is linked to tooth decay as it sits under the banner of poor diet.

A lot of this comes down to a lack of education though. How do you find parents are when you are dealing with them? At the end of the day it's really their fault their child finds themselves under your care.

LL Getting someone to change their behaviour is one of the most difficult things to do. It took a lifetime to do it with tobacco, and that change is something we try to instil here. Parents may know that they should be brushing their child's teeth twice a day and should have regular dental visits, but I find it's the short term decisions that have a profound effect. It can be really tough.

The difficulty we have here is our paediatric department is massively overstretched to breaking point as it is, and the system is crying out for someone with the right knowledge to come in and educate parents to ensure they never find themselves in here again.

RP When they come to us the horse has already bolted. The disease has run its fullest course possible and there is no alternative. They have to come in for an operation under anaesthetic which, coupled with the inevitable guilt, denial and acceptance their parents will face, is extremely distressing.

Prevention messages have failed to their fullest possible extent, and it is not the right time to deliver it. Because of the nature of the problem we're 100\% operational so we struggle to implement a successful 
strategy that will help to tackle this, given the non-receptive audience we often encounter.

\section{How many children do you see a week?}

LL On average we run two lists a week and up to six patients on each list.

\section{Do the children realise the magnitude of what they're about to go through?}

RJ Sometimes they don't know at all. This is a big problem. Parents just don't tell them.

RP The best example is Mario (from Jamie's Sugar Rush). He skipped into the anaesthetic room, instantly built a rapport with Richard, only for 10 minutes later to be bleeding, be in an enormous amount of pain and want his mum. It was terrible to be a part of.

LL That happens all the time. It's sad. They come in happy. They leave crying.

RJ The process is potent in destroying trust. If parents don't tell their child what they're here for, it can be damaging.

\section{Does it have a knock-on effect later in life when they become adults?}

RP As a dentist who mainly treats adults I can say with great certainty that when I speak to people who haven't been to the dentist for a considerable amount of time, their story involves 'because when I was a child' or 'when I was younger'. Those childhood experiences just do not go away.

So in theory the problem will only get worse as those children become parents who don't or won't take their child to the dentist?

RJ This is my battle every day of the week. Parental anxiety projects itself onto the child who is just about to go under GA and that's largely why kids get very anxious. Generally speaking, a relaxed adult gives you a relaxed kid.

LL Kids just naturally want to trust you.

LF It's difficult to win that trust. If you do one thing wrong it is broken and you're back to square one. Because we're seeing so many patients we don't have the time to implement extensive behaviour management programmes to try and resolve that.

Is the area quite affluent with people regularly attending check-ups?

RP Not really. We see a lot of people with low income and deprivation is quite high.

\section{I guess that is reflected in what you see in mouths and what parents say?}

LL Yes it is. We see a lot of families who clearly do not prioritise their oral health. We see a lot of children with special needs and behavioural difficulties, and cutting back on sugar is the last thing on their minds.

PD The problem is we are seeing patients who were here two years ago for the very same thing. They have been through the entire process, dealt with the emotional grief that comes with it and still they haven't learned. It's soul-destroying.

\section{You were featured at the start} of Jamie Oliver's Sugar Rush. What has the reaction been amongst parents and adults to the programme?

LF A few parents have mentioned it, which is good to know. I think they may have been parents who either didn't realise how bad sugar is, or how much sugar is found in everyday foods. I even had one lady tell me she had thrown out all of the food in her house containing sugar after watching it!

RP It was only a couple of days ago the government threw out the sugary drinks tax petition in seven minutes. For it to gain something like 130,000 names in just over 24 hours speaks volumes for the reaction.

LL I was surprised by the number of people who actively agreed to extra tax. It shows a growing support for something to be done.

If the number of children being admitted for GA doesn't stabilise and continues to get worse, where do you see your departments in five years' time?

RJ I know I will be really, really, really busy. We don't have enough existing staff to cope with the demand we have now. 
RP In the dental department this has already begun.

LL You're not wrong! We're already firefighting. By the time we've ticked two or three children off the lists, another three or four have been added. It's never-ending.

RP Because demand far outweighs the resources available one of my responsibilities was to call a meeting earlier in the year with Public Health England (PHE), amongst others, to discuss a clinical network we could put in place to reduce the burden on us. I threatened to lock the doors until we figured it out. We need more anaesthetists, more support staff and more nurses if we are to cope with the growing demand. We get financially penalised for any delays too, which is the ridiculous paradox we find ourselves in.

LF At the moment we don't even have an adequate number of paediatric dentists to look after the patients we have. If this increases we are going to have to shut the doors and work on a postcode system like King's College do.

RP If we were to look at our situation from a taxpayer's perspective and take someone like Richard and look at his skills. He anaesthetises children, who are morbidly and mortally ill at times, and he is being dragged out of those sessions and we're asking him for more time to treat a disease that is totally preventable. It just isn't fair on those children who need it the most.

We have tariffs for everyone's time. For everyone here, that tariff is $£ 900$ per child. That is a lot for any situation, let alone a preventable disease. To me, that is shocking.

LL It's the same for Miss Foo though. She can have patients with severe trauma and complex dental needs, but her time is being allocated to children with dental problems. Children are waiting for a long time purely because our books are full with extractions. That's not right.

\section{Is this a similar story in other hospitals across London?}

RP Definitely. Kings are doing a Saturday list every week. The government wanted seven day working, and here we are with six at one of the largest teaching hospitals in the UK, to deal with a preventable disease.

RJ We're at the end of the line for this disease. More needs to be done to reverse this situation. It's incredibly challenging at the best of times.

LL We should be the last resort, but we're becoming the norm. That's how prevalent this is.

\section{What one thing would you like to see changed that would make your job easier?}

RJ I would like to see a subsidy on healthy foods. It can't be right that fruit and vegetables are more expensive than chocolate bars and sugary drinks.

LF I would love to see water fluoridation rolled out across the country.
'It can't be right that fruit and vegetables are more expensive than chocolate bars and sugary drinks' 